\title{
The Clubhouse phenomenon: do we need another social network?
}

\author{
Wadim Strielkowski \\ University of California, Berkeley, Giannini Hall, CA 94720 Berkeley, United States, e-mail: \\ strielkowski@berkeley.edu \\ Prague Business School, Werichova 29, 15200 Prague, Czech Republic, e-mail: strielkowski@pbs- \\ education.cz
}

\begin{abstract}
Being a combination of the conference call, talkback radio, audio podcast, and an online video chat, Clubhouse is a new social networking app that gained over 10 million users and over $\$ 100$ in valuation in just 8 months. Unlike other social networks, it offers a real-time streaming audio chat that does not ask users to share any unnecessary information like exchanging text messages, conducting video calls, or sharing photos. Instead, Clubhouse users can listen to real-time conversations, contribute to these conversations and create their own conversations for the others to listen and to interact with. Often nicknamed a "Silicon Valley's hottest start-up", Clubhouse positions itself as an "exclusive" and "alternative" social network that attracts various celebrities and people who just want to talk to each other. Launched in March 2020, amidst the COVID-19 pandemic with its social distancing and lockdowns, Clubhouse offered its users a space for the digital group psychotherapy where people could solve their problems by talking them through with strangers. However, it is unclear what is going to happen to this new social network in the postpandemic world after all of its hype eventually evaporates. This paper discusses the possible underlying motives for the Clubhouse creation and its real purposes. Moreover, it looks at the three possible scenarios of its further development.
\end{abstract}

Keywords: social networks, digital surge, COVID-19 pandemic, technology industry, Clubhouse

\section{Introduction}

Clubhouse is the first social network app that does not require its users to look at their screens. Currently, it is an invitation-only app that works on iPhones (a version for Android is currently under construction) and offers a new mode of social networking through audio chats conducted in real time. Nothing is supposed to be recorded or stored - the app is envisaged as an alternative to attending a public speech or a lecture. Being at Clubhouse reminds a group narrative therapy (or group discussion) that are often used in psychology for treating mental disorders and chronic pain (Adler et al., 2008; or Phillips, 2017).

Launched amidst the COVID-19 pandemic, Clubhouse was able to hit the nail on the head when it offered people who were suddenly locked up in their homes a novel way to express themselves and to interact with each other. Even though other social network apps like Zoom, MS Teams, WebEx, or Google Meet already existed before, all of them offer a "formal" way of interacting with the others that includes talking on camera or showing presentation slides or documents that requires certain dress code and concentration. Millions of people who had to spend endless hours on "home office" entangled in the endless videoconferences simply need to let off the steam by purposelessly chatting with the others.

Clubhouse users can listen to various conversations, contribute to these conversations, as well as to create their own conversation in "chat rooms", nevertheless without being able to record or store 
these conversations for later use. In addition, Clubhouse applies a clever marketing strategy by trying to maintain an image of exclusiveness and elitism which is supported by famous businessmen, actor, singers, performers and politicians frequently appearing in its chat rooms to express their personal opinions on a number of hot topics. In its first months of existence, Clubhouse became a true social phenomenon that attracted many celebrities such as Tesla and SpaceX CEO Elon Musk or Facebook CEO Mark Zuckerberg. There is a large social component to Clubhouse that allows users to create and connect spaces where all kinds of topics are discussed, and it strongly promotes the formation and growth of networks. Famous entrepreneurs, politicians, actors and musicians all appear as speakers on Clubhouse taking part in the discussions on many interesting topics (see Figure 1).

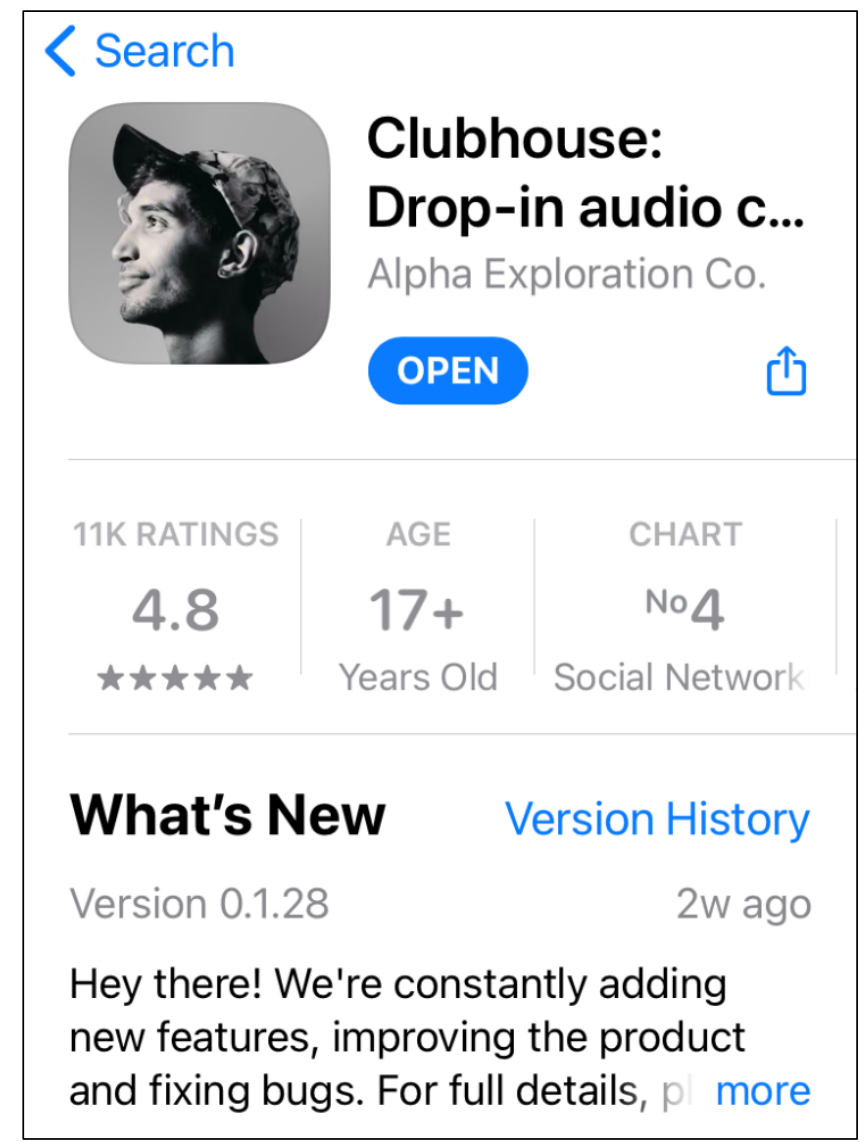

Figure 1. Clubhouse page at App Store

Source: App Store (2021)

However, it is not yet clear what Clubhouse is going to become and how it is going to evolve. Do we need another social network when we already have so many? What was the original intention or the underlying idea of Clubhouse creators? This short paper attempts to answer all these questions and sheds some light on the Clubhouse phenomenon.

\section{The rise of the new phenomenon}

The new social network phenomenon was created by Paul Davison and Rohan Seth, two Stanford University graduates with a broad experience in IT companies. Paul Davison received his Bachelor of Sciences in Industrial Engineering from Stanford University 2002 and his MBA from Stanford University Graduate School of Business in 2007. Later, he worked at CoinList, a crypto project that "empowers communities to invest in and trade new digital assets and develop on top of their networks" (CoinList, 2021). Rohan Seth received his Bachelor of Sciences in Computer Science in 2006 and his Master of Sciences in Management Science and Engineering in 2008 (both from Stanford University. Later he worked at Opendoor, a company with a mission to "simple way to buy, sell or 
trade-in a home" (Opendoor, 2021), Memry Labs, an IT company that created such iPhone apps as Phone-a-Friend (finding a friend who is free to talk on one's commute) and Hashtag (chat room for schools), as well as Google (almost 6 years in engineering). The duo launched Clubhouse, their joint project that offered a live streaming audio chat without the nuisance of video calls, text messaging or monetization in April 2020.

Right from its very beginning, Clubhouse started to position itself as an alternative social network with a hint of exclusiveness (one can join using an invitation from the existing Clubhouse user) that created a hype effect and even pushed some potential users to buy their invitations from strangers (Gkritsi, 2021). The social network applied an interesting way of presenting its brand using model of the "rotating app icon" that features photographs of its community members that are switched every few weeks (see Figure 2).

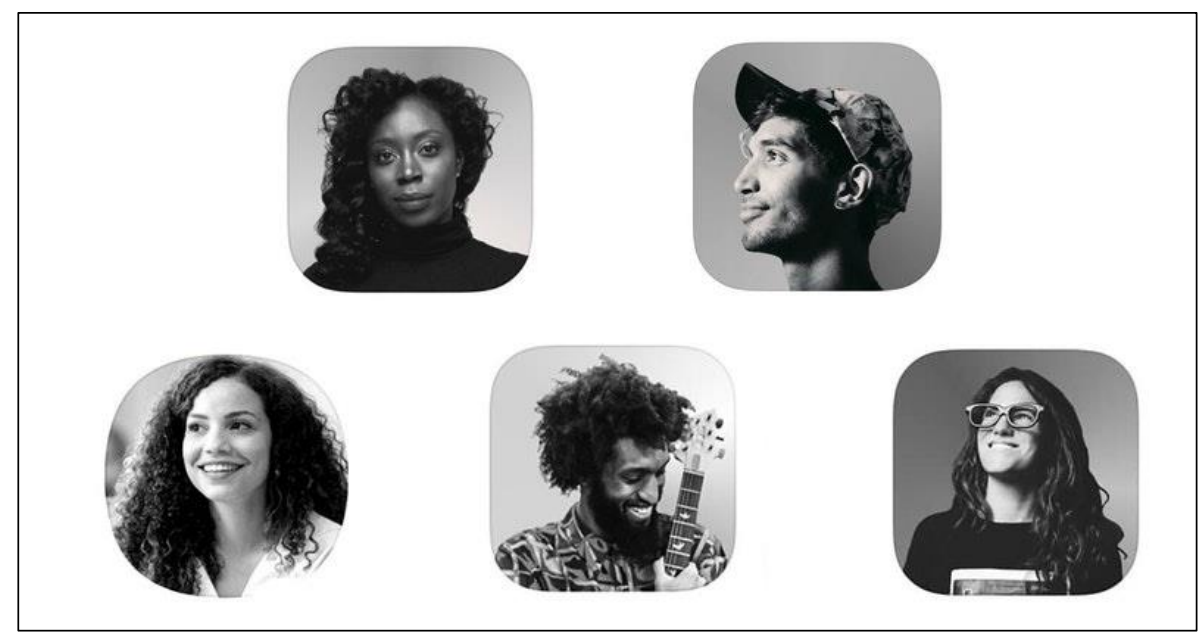

Figure 2. Examples of the Clubhouse rotating app icon

Source: Rodriguez (2021)

There is no doubt that Clubhouse represents a new Internet social phenomenon. However, this phenomenon could have only emerged amidst the COVID-19 pandemic with its social distancing and lockdowns. As a result of the pandemic, clubs, cafes and restaurants all around the world were shut down, concerts and live events were cancelled and many people found themselves in social isolation. The troubling increase of anxiety and depression cases as a result of anti-coronavirus measures were reported from all around the world (Faisal et al., 2021; Jiang et al., 2021). Even though the coronavirus pandemic might have triggered innovations in business and academia (for instance, in a form of the Schumpeterian 'creative destruction' (see Strielkowski, 2020)), lots of people might be simply tired of being on home office and running constant videoconferences and meetings. In a way, modern technology might have helped people to connect more but paradoxically it also have made lots of them to feel even lonelier and excluded (see Fernandez and Matt, 2020; or Hartt, 2021). It appears that what many people miss is a simple conversation and Clubhouse was able to offer them this - simple and clear.

\section{What is the real purpose of Clubhouse?}

Clubhouse appeared on the market thanks to the growing demand for informal real-life-like online conversations. All Clubhouse conversations are real-time which means one can hear people throwing out their opinions on the subject and raising her or his hand to throw theirs. Unlike other social networks, it offers a certain form of an online audio narrative therapy that is used for the development of social and emotional skills or for treating the substance use and mental disorders (Beaudoin et al., 2016; or Wendt et al., 2017). The name of the Clubhouse app bears the striking resemblance to the so-called "Clubhouse model" which represents a type of a psychosocial rehabilitation for the patients with mental health disorders that makes them to actively engage with 
their communities and to participate in their social lives by using various programs and services (Mutschler et al., 2021).

Clubhouse quickly gained worldwide popularity already reporting an impressive number of over 10 million downloads as of February 2021 (see Figure 3).

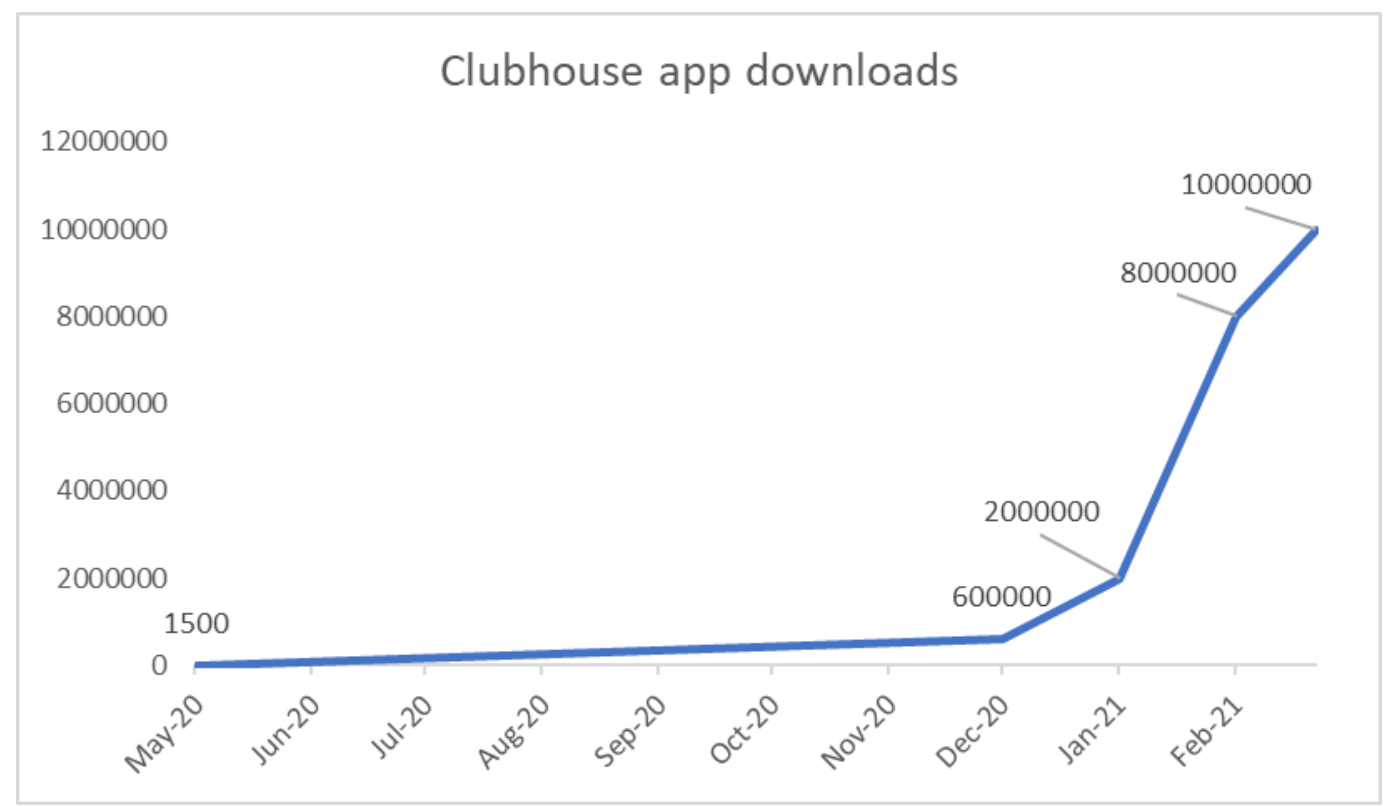

Figure 3. Clubhouse app downloads in 2020-2021

Source: Singh (2021)

It received a nickname "Silicon Valley's hottest start-up" and yielded an unprecedented valuation increase in just over six months: from $\$ 100$ million to $\$ 1$ billion (Levy and Rodriguez, 2020; Solis, 2021).

However, the question is what is the real purpose of Clubhouse might be after all. It was created by the people who worked in Google and other IT companies and therefore there might be some underlying motive for its creation. One of the possibilities might be a testing site for speech recognition. Artificial Intelligence (AI) is increasingly used in speech recognition and mimicking conversations. In the recent years, virtual voice assistants such as Siri, Google, or Alexa became ubiquitous. However, more work is required on voice and speech processing and lots of Big Data is needed to accomplish it. Clubhouse might offer lots of testing material for the advancement of this technology.

\section{Possible scenarios of the Clubhouse app development}

One might wonder whether Clubhouse is going to end up as yet "another social network" like its predecessors, such as Facebook, Twitter or Instagram, or whether it is going to develop into something more interesting and inspiring. In general, one can see that there might be three pathways for Clubhouse further development: First, it might profile itself into something of a "group psychotherapy" social network where people would relieve themselves off their troubles and problems by talking about them to strangers. This development might be very interesting and it would create the opportunity for this social network to keep its enigmatic and exclusive touch. Of course, this option would entail many demands and challenges such as the chats privacy or audio recording ban. Data spillage from Clubhouse audio chats have already been reported and this issue needs to be tackled in the future (Russon, 2021).

Second, in the few coming months or years Clubhouse might evolve into a "regular" social network which would open an unrestricted membership for everyone, as well as allow monetization and using third-party apps, such as streaming music and playing podcasts. By doing this, it might increase its pool of users but would inevitably lose its image of exclusivity and uniqueness turning 
into "just another" social network. This scenario seems quite real now when the creators of Clubhouse announced that monetary donations (a form of endorsing speakers) will be introduced by the end of March 2021.

Finally, a third option is that Clubhouse app might start losing its popularity when all the hype evaporates. According to Google Trends, the interest over time in the app is currently declining (Figure 4). This might be reversed after the Android version is launched but it is unlikely to reverse the trend and will merely copy it in a different magniture.

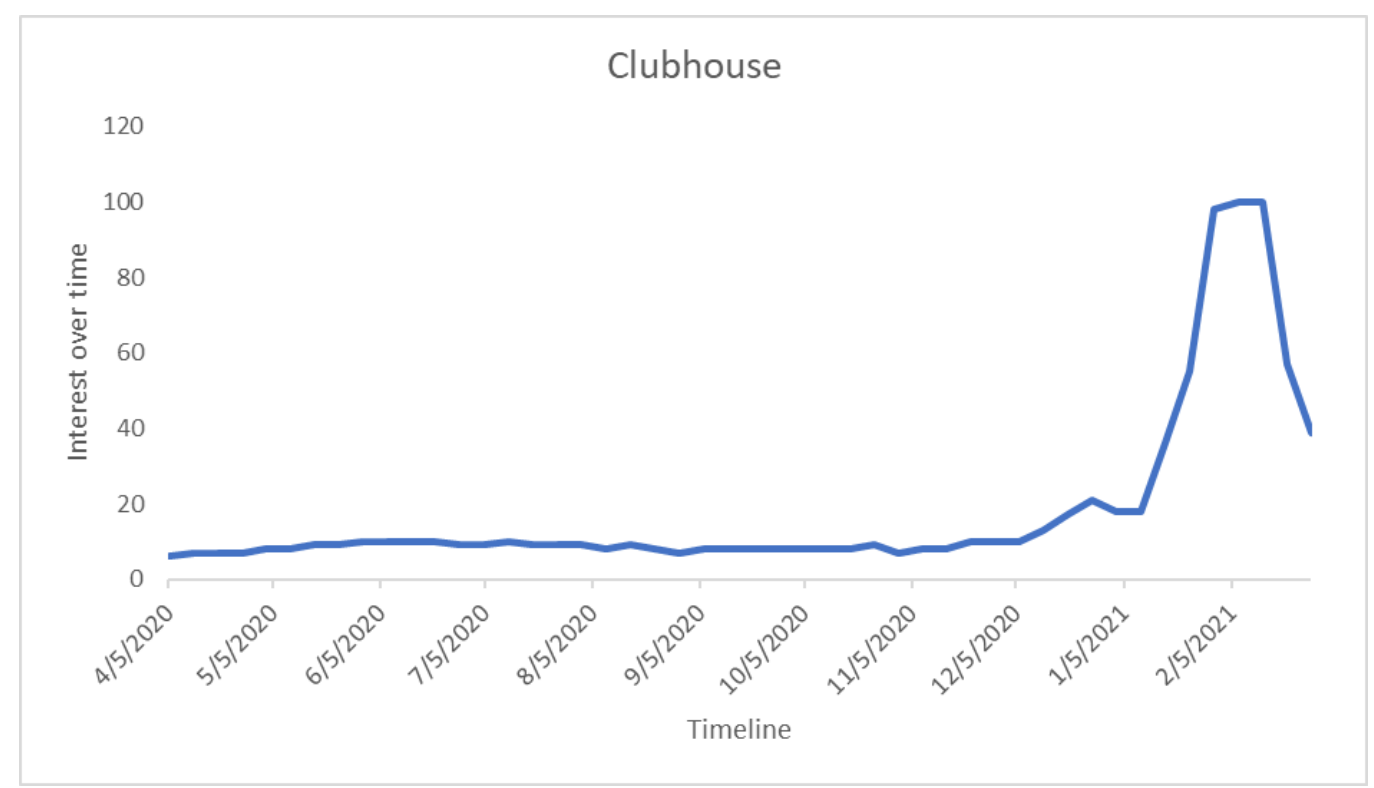

Figure 4. Clubhouse worldwide Internet searches (interest over time)

Source: Google Trends (2021)

This is what happened to the popular augmented reality gaming app Pokémon Go that reached over 500 million downloads in 2016 (Gilbert, 2016) but then users started losing their interest (see Figure 5). In this case scenario it might be simply shut down for business and personal use due to the low usage and lack of interest just as it happened to Google+, a social networking app from Google, that was in operation between 2011 and 2019.

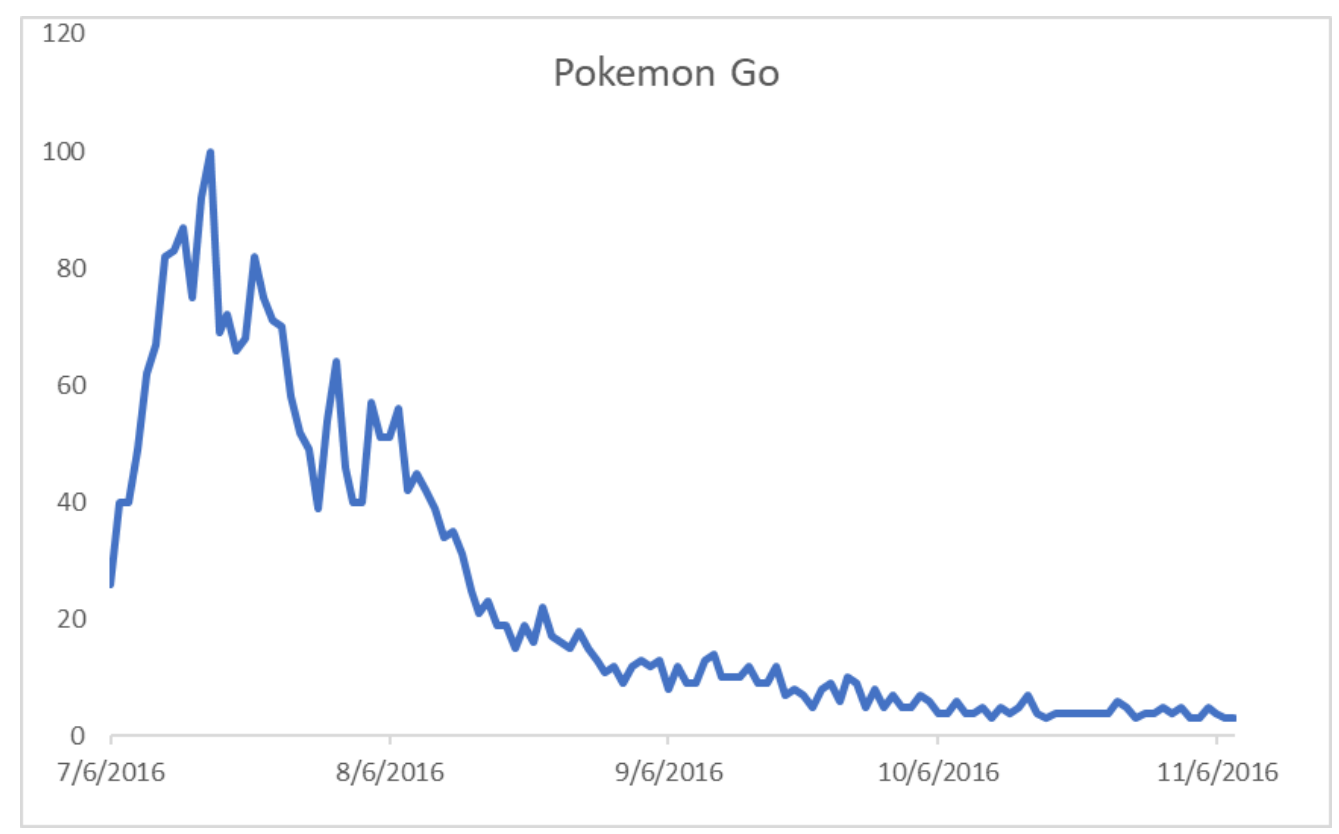

Figure 5. Pokémon Go worldwide Internet searches (interest over time)

Source: Google Trends (2021) 
The third scenario might occur when the COVID-19 pandemic is finally over thanks to the massive vaccination of the world's population - lockdowns and social distancing would then become a history, people would be able to go out and socialize as much as they want, and thence there would be no need for talking about one's problems in audio chats anymore. However, there is still lots of time for Clubhouse to evolve. The critical level of COVID-19 vaccination that is required to keep everyone safe is going to be reached by the end of 2021 or even later (Forni and Mantovani, 2021; Charumilind et al., 2021), Clubhouse still has some time to boost up its audience and profile itself.

\section{Conclusions}

Apple CEO Tim Cook once said that if the user does not pay for using of social networks or other ICT services, she or he is not a customer but a product (Lomas, 2021). He used these words the criticise Facebook in a famous confrontation between the two tech giants over who controls iPhone users' privacy but Apple or Alphabet (the parent company of Google) are basically operating on the same basis.

Currently, Clubhouse is riding on a wave of hype but it is another social network and all social networks are created for one reason - IT companies want to know everything about their customers in order to sell their data and make money. First, they found a way how to read our letters by offering us free e-mail services. Then, they started analysing our posts and conversations using Facebook. After that, they taught their algorithms and bots to scrutinise our text messages on Twitter and WhatsApp. Consequently, they learned how to examine our photographs and images using Instagram. Now, they might be using Clubhouse to learn how to capture everything that we are saying out loud.

Voice-recognition technologies that involve AI already exist but more Big Data is required to train the algorithms to talk to humans and to understand what the humans are saying. Clubhouse might be just a digital testing site for these voice-recognition algorithms. Perhaps, we will soon have AI talking to people in Clubhouse chat rooms and passing the Turing test without any difficulties.

\section{References}

- Adler, J. M., Skalina, L. M., \& McAdams, D. P. (2008). The narrative reconstruction of psychotherapy and psychological health. Psychotherapy Research, 18(6), 719-734. https://doi.org/10.1080/10503300802326020

- App Store (2021). Clubhouse: drop-in audio chat. Available at: https:/apps.apple.com/us/app/clubhouse-drop-in-audio-chat/id1503133294 (accessed on 04.03.2021)

- Beaudoin, M. N., Moersch, M., \& Evare, B. S. (2016). The effectiveness of narrative therapy with children's social and emotional skill development: an empirical study of 813 problemsolving stories. Journal of Systemic Therapies, 35(3), 42-59. https://doi.org/10.1521/jsyt.2016.35.3.42

- Charumilind, S, Craven, M., Lamb, J., Sabow, A., Wilson, M. (2021). When will the COVID19 pandemic end? Available at: https:/www.mckinsey.com/industries/healthcare-systemsand-services/our-insights/when-will-the-covid-19-pandemic-end (accessed on 23.02.2021)

- CoinList (2021). About us. Available at: https://coinlist.co (accessed on 03.03.2021)

- Faisal, R. A., Jobe, M. C., Ahmed, O., \& Sharker, T. (2021). Mental health status, anxiety, and depression levels of Bangladeshi university students during the COVID-19 pandemic. International Journal of Mental Health and Addiction, 1-16. https://doi.org/10.1007/s11469$\underline{020-00458-y}$

- Fernandez, L., \& Matt, S. J. (2020). Bored, Lonely, Angry, Stupid: Changing Feelings about Technology, from the Telegraph to Twitter. Harvard University Press 
- Forni, G., \& Mantovani, A. (2021). COVID-19 vaccines: where we stand and challenges ahead. Cell Death \& Differentiation, 28, 626-639. https://doi.org/10.1038/s41418-020-00720-9

- Gilbert, B. (2016). Pokémon Go has been downloaded over 500 million times. https://www.businessinsider.com/pokemon-go-500-million-downloads-2016-9?r=US\&IR=T (accessed on 02.03.2021)

- Gkritsi, E. (2021). Clubhouse invites for sale on Alibaba's used goods app. Available at: https://technode.com/2021/02/02/clubhouse-invites-for-sale-on-alibabas-used-goods-app (accessed on 23.02.2021)

- Google Trends (2021). Clubhouse. https://trends.google.com/trends/explore?q=Clubhouse (accessed on 04.03.2021)

- Hartt, M. (2020). COVID-19: a lonely pandemic. Cities \& Health, 1-3. https://doi.org/10.1080/23748834.2020.1788770

- Jiang, Y. (2021). Problematic Social media usage and anxiety among university students during the COVID-19 pandemic: the mediating role of psychological capital and the moderating role of academic burnout. Frontiers in Psychology, 12, 612007. https://dx.doi.org/10.3389/fpsyg.2021.612007

- Levy, A., Rodriguez, S. (2020). Silicon Valley is going crazy for Clubhouse, a social media app with 1,500 users that's already worth $\$ 100$ million. https://www.cnbc.com/2020/05/20/clubhouse-app-is-where-mc-hammer-and-jared-letochat-with-vcs.html (accessed on 02.03.2021)

- Lomas, N. (2021). Apple's Tim Cook warns of adtech fuelling a 'social catastrophe' as he defends app tracker opt-in. Available at: https://techcrunch.com/2021/01/28/apples-tim-cookwarns-of-adtech-fuelling-a-social-catastrophe-as-he-defends-app-tracker-opt-in/ (accessed on 04.03.2021)

- Mutschler, C., Junaid, S., \& McShane, K. (2021). Clubhouses response to COVID-19: member challenges and Clubhouse adaptations. Community Mental Health Journal, 1-14. https://doi.org/10.1007/s10597-020-00753-x

- Opendoor (2021). About us. Available at: https://www.opendoor.com (accessed on 06.03.2021)

- Phillips, L. U. (2017). A narrative therapy approach to dealing with chronic pain. International Journal of Narrative Therapy \& Community Work, (1), 21-30.

- Rodriguez, S. (2021). How Black users are saving Clubhouse from becoming a drab hangout for tech bros. Available at: https://www.cnbc.com/2021/01/10/black-users-turned-social-appclubhouse-from-drab-to-fun.html (accessed on 04.03.2021)

- Russon, A.-M. (2021). Clubhouse confirms data spillage of its audio streams. Available at: https://www.bbc.com/news/business-56163623 (accessed on 23.02.2021)

- Singh, J. (2021). Clubhouse Crosses 10 Million Downloads Globally on the App Store. Available at: https://gadgets.ndtv.com/apps/news/clubhouse-downloads-10-million-appleapp-store-installs-us-india-russia-sensor-tower-2376172 (accessed on 03.03.2021)

- Solis, B. (2021). Latest Silicon Valley unicorn, Clubhouse, raises \$100 million; accelerates rise of audio-based social networking. Available at: https://www.forbes.com/sites/briansolis/2021/01/26/the-latest-silicon-valley-unicornclubhouse-raises-100-million-and-also-raises-attention-to-the-importance-of-audio-basedsocial-networking/?sh=7853e8a523a6 (accessed on 22.02.2021)

- Strielkowski, W. COVID-19 Pandemic and the digital revolution in academia and higher education. Preprints, 2020, 2020040290. https://doi.org/10.20944/preprints202004.0290.v1

- Wendt, D. C., \& Gone, J. P. (2017). Group therapy for substance use disorders: A survey of clinician practices. Journal of Groups in Addiction \& Recovery, 12(4), 243-259. https://doi.org/10.1080/1556035X.2017.1348280 